\title{
MUTUAL INSURANCE, INDIVIDUAL SAVINGS AND LIMITED COMMITMENT
}

\author{
ETHAN LIGON, JONATHAN P. THOMAS, AND TIM WORRALL
}

\begin{abstract}
This paper examines a dynamic model of mutual insurance when households can also engage in self-insurance by storage. This mutual insurance is informal as it is assumed that there is no enforcement mechanism, so any mutual insurance arrangements must be self-enforcing. It is shown how consumption allocations satisfy a modified Euler condition and that an enhanced storage technology can either raise or diminish welfare. Furthermore it is shown that the ex ante transfers introduced into dynamic informal insurance models recently by Gauthier, Poitevin, and González (1997) are only used here in the first period, with the role of ex ante transfers being replaced by differential individual storage.
\end{abstract}

\section{INTRODUCTION}

This paper considers a dynamic model of informal insurance in which households face fluctuating endowment streams but can offer mutual insurance or income smoothing by transferring income between themselves. It is assumed that there are no enforceable contracts, and hence any implicit insurance arrangement is appropriately modelled as a noncooperative equilibrium. It is the possibility of benefitting from future insurance which acts as an incentive for the current providers of insurance, typically those with a current abundance, to keep to the informal arrangement. The focus of the paper is on efficient (subgame perfect) equilibria of such games.

Informal insurance in this context has been studied by Thomas and Worrall (1988), Kletzer and Wright (1996), Kocherlakota (1996), Ligon, Thomas, and Worrall (1997), and Gauthier, Poitevin, and González (1997) amongst others. Some of the potential empirical implications of these models have been drawn by Hayashi (1996), Foster and Rosenzweig (1995), Platteau (1996), Ligon, Thomas, and Worrall (1997) and Kocherlakota (1996). Despite the dynamic nature of the equilibria studied in these papers, the underlying models are static in the sense that endowment cannot be transferred between periods (although there may be some dependency between periods if endowments follow a Markov process). A major question left

Date: May 13, 1998. 
unanswered is whether the results are robust to the introduction of intertemporal substitution possibilities, such as would be provided by intertemporal production, storage, or access to an external credit market. As a first step towards answering this question, we introduce a linear intertemporal production/storage technology. Formally the model becomes a dynamic game, in which the state variable is the capital stock or savings of the households.

Intertemporal substitution technologies, assumed available to each household, imply that households are less reliant on others for insurance purposes, since self-insurance is now possible (i.e., save in good years and dissave in bad ones). On the other hand, the group of households as a whole can now self-insure, and thus smooth aggregate shocks over time. One of the questions which we look at below, after outlining the model in Section 2, is whether the introduction of a storage technology is necessarily welfare improving. In Section 3, we find that in fact the welfare effects of storage are ambiguous. It is possible that the higher utility from self-insurance implies that mutual insurance is more difficult to sustain; a household which could transfer income to another facing a bad shock may prefer instead to remain in autarky, and this reduction of mutual insurance due to the introduction of storage can outweigh the beneficial effects.

A second question concerns the dynamics of consumption. We show that the usual Euler equation characterising consumption growth is modified by a term reflecting the effect that a household's saving has on its temptation to deviate from the equilibrium in the following period, assuming that it consumes this extra unit. The sign of this term depends in each state on whether the equilibrium consumption level exceeds or is less than autarky consumption. A third issue that we investigate relates to the question of whether ex ante transfers, that is to say transfers made at the beginning of a period before the current shock is known, are beneficial in improving risk sharing. Without storage, Gauthier, Poitevin, and González (1997) show that such transfers are beneficial. In our framework, it turns out that storage can accomplish the same effect as ex ante transfers, and consequently the possibility of ex ante transfers does not enhance the set of equilibria.

A second major task of this paper is to develop a computational approach to solve dynamic limited commitment models of the type considered here. This we do in Section 4 of the paper. In addition, Section 5 discusses a number of computed examples meant to illustrate the properties of the model. An interesting feature of the examples is that they show that, if there is to be storage, the household which receives most surplus from mutual insurance will store the most. This makes good sense, as storage increases the autarky utility, and a 
household which anticipated small returns from the relationship would be more inclined to renege. The examples also illustrate the welfare properties of our model and address the issue of ex ante transfers.

\section{The Model}

Suppose that there is a finite set of households $\mathcal{H}$ where $\mathcal{H}=\{1, \ldots, H\}$ and $H \geq 2$. Each period $t=1,2, \ldots$, household $i$ receives an income $y_{s}^{i}>0$ of a single good, where $s$ is the state of nature drawn from a finite set $\mathcal{S}=\{1, \ldots, S\}$ with $S \geq 2$. It is assumed that the state of nature follows a Markov process with the probability of transition from state $s$ to state $r$ given by $\pi_{s r}$, and we assume that $\pi_{s r}>0$ for all $r$ and $s .{ }^{1}$ We assume that there is some initial distribution over period 1 states $r$ given by $\pi_{r}^{0}$. This formalisation includes as a special case an identical and independent distribution over the possible states of nature $\left(\pi_{s r}\right.$ is independent of $\left.s\right)$.

Each household $i$ has access to a linear storage technology which allows it have one unit of the good available at the beginning of $t+1$ if $\rho$ units are stored at the end of $t$, where $\rho>0$. The level of stocks available to household $i$ at the beginning of period $t$ is denoted $k^{i}(t)$ where $k^{i}(1) \geq 0$ is given. We shall impose the condition that $k^{i}(t) \geq 0$ for all $t=1,2, \ldots$ If $\rho=\infty$, then no storage is possible. If $\rho>1$, then the good stored is subject to depreciation. If $\rho<1$, this technology may also be interpreted as access to a simple credit market with a positive interest rate, where borrowing is excluded (a translation of origin would allow borrowing subject to a credit constraint to be studied). ${ }^{2}$

Household $i$ has a twice continuously differentiable Bernoulli utility of consumption function $u_{i}\left(c^{i}\right)$, where $c^{i}$ is consumption. It is assumed that $c^{i} \geq 0$. Households are risk averse, with $u_{i}^{\prime}\left(c^{i}\right)>0, u_{i}^{\prime \prime}\left(c^{i}\right)<0$ for all $c^{i}>0$. Households are infinitely lived, discount the future with common discount factor $\delta$, and are expected utility maximisers. We assume that if $\rho<\delta$ then each $u_{i}(\cdot)$ is bounded above in order to ensure boundedness of discounted utilities.

We briefly describe the autarky problem facing household $i$ excluded from mutual insurance. In each period $t$, having observed the current state $s$, she has $z_{s}^{i}(t)=k^{i}(t)+y_{s}^{i}(t)$ total resources available. She then chooses consumption $c^{i}(t)$, and stores the remainder. We let

\footnotetext{
${ }^{1}$ Nothing important depends on this assumption that all transition probabilities are positive.

${ }^{2}$ If the return on each unit stored can be made state-contingent, contrary to our assumption, then an argument given by Bulow and Rogoff (1989) shows that at some point at least one household will prefer autarky and therefore only autarky is sustainable.
} 
$Z_{s}^{i}\left(z_{s}^{i}(t)\right)$ denote the autarky utility of household $i$ in state $s$ if its resources available at the beginning of the period is $z_{s}^{i}(t)$. It represents the utility available from self-insurance only and can be recursively formulated as

$$
Z_{s}^{i}\left(z_{s}^{i}(t)\right)=\max _{k^{i}(t+1) \geq 0}\left\{\left(u_{i}\left(z_{s}^{i}(t)-\rho k^{i}(t+1)\right)+\delta \sum_{r=1}^{S} \pi_{s r}\left(Z_{r}^{i}\left(k^{i}(t+1)+y_{r}^{i}(t+1)\right)\right\} .\right.\right.
$$

It is well known that the autarky value function in (1) inherits the properties of the Bernoulli utility function. It is increasing, differentiable and strictly concave and denoting autarky consumption by $\hat{c}_{s}^{i}\left(z_{s}^{i}(t)\right)$, it satisfies the envelope condition

$$
\frac{\partial Z_{s}^{i}\left(z_{s}^{i}(t)\right)}{\partial z_{s}^{i}(t)}=u_{i}^{\prime}\left(\hat{c}_{s}^{i}\left(z_{s}^{i}(t)\right)\right)
$$

Moreover, it is straightforward to show that it is decreasing in $\rho$.

In general, however, each household can make and receive transfers from other households after the current state is known, and before consumption is realised allowing a potential Pareto improvement. The precise timing and strategic possibilities are as follows. At date $t$, each household is aware of the previous history of shocks and all past moves of other households, and also the state of the world, $s$, occurring at date $t$. The total resources of household $i$ at this point are $z_{s}^{i}(t)$. Household $i$ then chooses a transfer $\tau^{i j} \geq 0$ to be made to each other household $j \neq i$. Simultaneously, household $i$ specifies a consumption level $c^{i} \geq 0$. At the same time, each household $k$ must specify the "acceptable" transfers, $\left(\tau_{(k)}^{i j}\right)_{i \neq k}$, and consumption levels, $c_{(k)}^{i}$, of each other household $i \neq k$. The interpretation of these is that they are the levels agreed according to some implicit arrangement. Next, a "transfer mechanism" allocates transfers and consumptions as specified by the household concerned, given that each household acts according to the "acceptable" specifications given by the other households, that is, provided both

$$
\begin{aligned}
c^{i} & =c_{(k)}^{i} \quad \forall i, k \in \mathcal{H} \quad \text { with } \quad i \neq k \\
\tau^{i j} & =\tau_{(k)}^{i j} \quad \forall i, j, k \in \mathcal{H} \quad \text { with } \quad i \neq j, k
\end{aligned}
$$

and provided that the transfer allocation is feasible. This requires that no household $i$ 's net transfer to others exceeds her resources $z_{s}^{i}(t)$, and that end of period storage, $z_{s}^{i}(t)+$ $\sum_{j \neq i}\left(\tau^{j i}-\tau^{i j}\right)-c^{i}$ is non-negative. If these conditions are satisfied, then transfers are made, and consumption is realised. If either (3), (4) or feasibility fails, then no transfers are made and each household is given a subsequent move at which she chooses consumption 
unilaterally. Pure strategies can now be defined in the obvious way for this repeated extensive form game with "almost perfect information". In this part of the paper we restrict attention to equilibria in pure strategies only. In the computation section, to avoid nonconvexities, a randomization device will be introduced to the framework.

An interpretation of the transfer mechanism is that households gather at the transfer/consumption stage. There is an implicit understanding of what transfers and consumption levels should be (given by the common "acceptable" levels). If any household deviates from the specified transfers or consumption level, the entire agreement fails and households are left in autarky for that period. An important feature of this mechanism is that a household cannot take a positive transfer from other households and then deviate from the implicitly agreed consumption (and hence saving) level. The idea is that if a household engages in the transfers, she is under social pressure to conform at the consumption level, for example because she is in the same location as the other households. ${ }^{3}$ The household always has the option of staying out of the mechanism altogether (captured, for example, by choosing all transfers to other households at zero and consumption at the desired autarkic level). ${ }^{4}$ An alternative approach would be to suppose that storage is communally held. This may be appropriate in some village economy contexts, where an authority, such as the local priest, controls the store. This would primarily change the payoff a household could achieve from deviation since access to the store could be denied, ruling out any self insurance.

In order to identify pure-strategy subgame perfect equilibria, the following observations can be made. First, an optimal punishment is the minmax punishment of a mutual reversion to autarky (implemented by specifying zero transfers each period). This is clearly subgame perfect. In other words, failure to abide by the implicit insurance arrangement leads to exclusion from all future communal insurance. Secondly, it is only necessary to consider the net aggregate transfer - as opposed to all the bilateral transfers - to or from each household in determining whether a strategy combination is in equilibrium, since this is all that matters

\footnotetext{
$\overline{{ }^{3} \text { Conceptually }}$ it may be preferable to allow a household to take a (possibly positive) transfer and then renege at the consumption/storage stage. Indeed, this would eliminate the need for the above described mechanism involving the specification of "acceptable" transfers and consumption levels. It would, however, considerably complicate the characterisation (and computation) of efficient equilibria which is developed below, as it would add a second decision point within each period at which deviation incentives have to be checked.

${ }^{4} \mathrm{~A}$ single household can nullify the entire mechanism. Because we are looking at Nash equilibria, this assumption is unimportant. Were we to consider coalitional deviations, it would be appropriate to refine the mechanism to allow coalitions to carry out transfers independently of non-coalition members. An analysis of coalitional deviations in an informal insurance context is considered by Fafchamps (1995).
} 
to an individual household when considering a deviation (the above mechanism, in particular, does not allow a household to take in transfers from other households and renege on her own transfers to others).

Before turning to efficient outcome paths we start with a characterization of any purestrategy equilibrium outcome path. Note that any outcome path can be described by a mapping from histories of exogenous shocks to actions (transfers/consumption levels). Specifically, let $s_{t}$ be the state of the world occurring at date $t$. An outcome path will specify for every date $t$ and for each history of states up to and including date $t, h_{t}=\left(s_{1}, s_{2}, \ldots, s_{t}\right)$, and each household $i$, a net transfer $\tau^{i}\left(h_{t}\right):=\sum_{j \neq i}\left(\tau^{i j}\left(h_{t}\right)-\tau^{j i}\left(h_{t}\right)\right)$ to be made by household $i$ to all other households (a negative transfer signifying a transfer in the opposite direction), where $\tau^{i j}\left(h_{t}\right)$ denotes the realised transfer from $i$ to $j$ at $t$ after $h_{t}$ (zero whenever (3), (4) or feasibility fail). Likewise it will specify a consumption level $c^{i}\left(h_{t}\right)$ (as determined by either the transfer mechanism or a subsequent consumption decision). Notice that by construction $\sum_{i} \tau^{i}\left(h_{t}\right)=0$. Let us define $U_{t}^{i}\left(h_{t}\right)$ to be the expected discounted utility of household $i$ from the outcome path from period $t$ onwards, discounted to period $t$, if history $h_{t}=\left(h_{t-1}, s_{t}\right)$ occurs up to period t (i.e., when the current state $s_{t}$ is known): ${ }^{5}$

$$
U_{t}^{i}\left(h_{t}\right)=u^{i}\left(c^{i}\left(h_{t}\right)\right)+\mathrm{E}\left[\sum_{n=t+1}^{\infty} \delta^{n-t} u\left(c^{i}\left(h_{n}\right)\right) \mid h_{t}\right],
$$

where E denotes expectation. Then household $i$ will have no incentive to deviate from the equilibrium path if the following sustainability constraint holds at each date $t$ after every history $h_{t}$,

$$
U_{t}^{i}\left(h_{t}\right) \geq Z_{s_{t}}^{i}\left(k^{i}\left(h_{t-1}\right)+y_{s_{t}}^{i}\right)
$$

where $Z_{s_{t}}^{i}\left(k^{i}\left(h_{t-1}\right)+y_{s_{t}}^{i}\right)$ is the continuation autarky utility for household $i$, from $t$ onwards, discounted to period $t$, on the assumption she had followed the equilibrium up to $t-1$ (and hence has resources $k^{i}\left(h_{t-1}\right)+y_{s_{t}}^{i}$ at $t$ where $k^{i}\left(h_{t-1}\right)$ is the beginning of period $t$ storage on the equilibrium path). If (6) holds for all $i$ and all $h_{t}$, then the outcome path corresponds to an equilibrium.

Within the class of equilibrium outcome paths, we shall characterise the constrained efficient outcome paths, those which are not Pareto-dominated by any other sustainable outcome path. A straightforward dynamic programming procedure can be followed. This relies

\footnotetext{
${ }^{5}$ For period $1, h_{t-1}$ is the empty set.
} 
on two key facts. First, the Markov structure implies that the problem of finding an efficient continuation path is the same at any date at which the same state of nature occurs and storage is the same. Secondly, an efficient path must, after any history, have an efficient continuation path. The reason why all continuation paths should be efficient is simply that all constraints are (at least weakly) relaxed by moving from an inefficient path to a Pareto dominating continuation path that satisfies the sustainability conditions - such a move will make the overall path Pareto superior to the original one. This dynamic programming problem is similar in structure to that analysed by Thomas and Worrall (1988) amongst others. Similar arguments can be applied in the current context.

A key difference in the current paper is the existence and evolution of storage. The levels of individual storage evolve according to the following state equations:

$$
\begin{aligned}
k^{i}(t+1) & =(1 / \rho)\left(z_{s}^{i}(t)-\tau_{s}^{i}(t)-c_{s}^{i}(t)\right) \quad \forall i \neq H \\
k^{H}(t+1) & =(1 / \rho)\left(z_{s}^{H}(t)+\sum_{i=1}^{H-1} \tau_{s}^{i}(t)-c_{s}^{H}(t)\right)
\end{aligned}
$$

Using equation (7) to eliminate $\tau_{s}^{i}(t)$ in equation (8) shows that

$$
c_{s}^{H}(t)=z_{s}(t)-\rho k(t+1)-\sum_{i=1}^{H-1} c_{s}^{i}(t)
$$

where $k(t)=\sum_{i=1}^{H} k^{i}(t)$ denotes the aggregate level of storage at the beginning of date $t$ and where $z_{s}(t)=k(t)+\sum_{i=1}^{H} y_{s}^{i}(t)$ is the total resources available at date $t$ in state $s$.

From this and the Markov structure of incomes, and because each of the sustainability constraints are forward looking, the set of equilibrium continuation paths depends only on the current state and level of resources available in that state. Viewed in utility space, the Pareto frontier relating the discounted continuation utility of household $H$ to that of the other households at any date $t$ and given the current state $s$ depends only on the current state and total resources available at that date in that state. We set up the programming problem at date $t$ so that the current state is $s$, and target utilities $U_{s}^{i}(t)$ are given (for all $i \neq H)$, as are beginning of period resource levels $z_{s}(t)$. We shall use $r$ to index the state in the following period. Choice variables are consumptions $c_{s}^{i}(t)$ for each household $i \neq H$, the continuation utilities $U_{r}^{i}(t+1)$ for each possible state $r$ in the next period and each household $i \neq H$ and the beginning-of-next-period levels of storage $k^{i}(t+1)$ for each household. The level of consumption for household $H$ is determined by equation (9). The 
value function for household $H$ can now be written to depend on the current target utilities and the current resource: $U_{s}^{H}\left(U_{s}^{1}(t), \ldots, U_{s}^{H-1}(t) ; z_{s}(t)\right)$. To simplify the presentation, we assume that $\lim _{c^{i} \rightarrow 0_{+}} u_{i}\left(c^{i}\right)=-\infty$, which allows us to disregard the non-negativity constraint on consumption. The dynamic programming problem is

$$
\begin{array}{r}
U_{s}^{H}\left(U_{s}^{1}(t), \ldots, U_{s}^{H-1}(t) ; z_{s}(t)\right)=\max _{\substack{\left(\left(c_{s}^{i}(t)\right),\left(U^{i}(t+1)\right)_{r=1}^{S}\right)_{i=1}^{H-1} \\
\left(k^{i}(t+1)\right)_{i=1}}} u_{H}\left(z_{s}(t)-\rho k(t+1)-\sum_{i=1}^{H-1} c_{s}^{i}(t)\right) \\
+\delta \sum_{r=1}^{S} \pi_{s r} U_{r}^{H}\left(U_{r}^{1}(t+1), \ldots, U_{r}^{H-1}(t+1) ; k(t+1)+y_{r}(t+1)\right)
\end{array}
$$

where $k(t+1)=\sum_{i=1}^{H} k^{i}(t+1)$ subject to the following constraints,

$$
\begin{array}{rc}
\lambda_{s}^{i}(t): & u_{i}\left(c_{s}^{i}(t)\right)+\delta \sum_{r=1}^{S} \pi_{s r} U_{r}^{i}(t+1) \geq U_{s}^{i}(t) \quad \forall i \neq H \\
\delta \pi_{s r} \phi_{r}^{i}(t+1): & U_{r}^{i}(t+1) \geq Z_{r}^{i}\left(k^{i}(t+1)+y_{r}^{i}(t+1)\right) \quad \forall r \in \mathcal{S} \quad \forall i \neq H \\
\delta \pi_{s r} \phi_{r}^{H}(t): & U_{r}^{H}\left(U_{r}^{1}(t+1), \ldots, U_{r}^{H-1}(t+1) ; k(t+1)+y_{r}(t+1)\right) \\
& \geq Z_{r}^{H}\left(k^{H}(t+1)+y_{r}^{H}(t+1)\right) \quad \forall r \in \mathcal{S} \\
\omega^{i}(t+1): & k^{i}(t+1) \geq 0 \quad \forall i \in \mathcal{H}
\end{array}
$$

Equation (10) represents the promise keeping constraints which show that each household must at least be given the level of expected discounted utility already promised. Equations (11) and (12) are the sustainability constraints, that no household has an incentive to deviate and equation (13) represent the non-negativity constraints for storage by each household. The constraint set is not convex because of the constraints (11) and (12). This implies that the value function may not be concave and in the computation section, we introduce the possibility of lotteries to convexify the problem and simplify computations of the optimum.

\section{RESUlts}


3.1. Solution. Using the first-order conditions for the dynamic programming problem described in the previous section, it can be shown that (see Appendix)

$$
\begin{aligned}
& u_{i}^{\prime}\left(c_{s}^{i}(t)\right)=\left\{\frac{\delta}{\rho} \sum_{r=1}^{S} \pi_{s r} u_{i}^{\prime}\left(c_{r}^{i}(t+1)\right)+\frac{\omega^{i}}{\rho \lambda_{s}^{i}(t)}\right\} \\
&+\frac{\delta}{\rho \lambda_{s}^{i}(t)} \sum_{r=1}^{S} \pi_{s r}\left\{\phi_{r}^{i}(t+1)\left(u_{i}^{\prime}\left(c_{r}^{i}(t+1)\right)-u_{i}^{\prime}\left(\hat{c}_{r}^{i}\left(z_{r}^{i}(t+1)\right)\right)\right)\right\} \\
& \forall s \in \mathcal{S} \quad \forall i \in \mathcal{H} \quad \forall t>0
\end{aligned}
$$

where for household $H, \lambda_{s}^{H}(t) \equiv 1$, and where $\hat{c}_{r}^{i}(z)$ denotes the optimal consumption of household $i$ in state $s$ under autarky, given that she enters the period with assets $z$. To interpret this condition first notice that if $\phi_{r}^{i}(t+1)=\phi_{r}^{H}(t+1)=0$ the last term on the right hand side of equation (14) is dropped. What is left is the familiar Euler equation from Life-Cycle theory (see, e.g., Hall (1978)) with an adjustment for the non-negativity constraint on storage. The parameter $\rho$ is the marginal rate at which consumption at date $t+1$ can be transformed into consumption at date $t$ i.e., $M R T_{t, t+1}=\rho$. The expected marginal rate of substitution between consumption at date $t$ and consumption at date $t+1$ for household $i$ is

$$
\operatorname{EMRS}_{t, t+1}^{i}=\frac{\delta \sum_{r=1}^{S} \pi_{s r} u_{i}^{\prime}\left(c_{r}^{i}(t+1)\right)}{u_{i}^{\prime}\left(c_{s}^{i}(t)\right)}
$$

So with $\phi_{r}^{i}(t+1)=\phi_{r}^{H}(t+1)=0$, each household obeys the condition that the expected marginal rate of substitution is less than or equal to the marginal rate of transformation, with strict inequality only if storage is zero. This condition of allocative efficiency for each household holds either if households act on their own, i.e., in the autarkic outcome where there is no risk-sharing, or if there is full commitment and complete risk-sharing.

To interpret equation (14) in the limited commitment environment, which takes account of the sustainability constraints, where $\phi_{r}^{i}(t+1)$ and $\phi_{r}^{H}(t+1)$ are typically non-zero, it is necessary to consider two further conditions which are derived directly from the first-order 
conditions given in the Appendix:

$$
\begin{aligned}
\lambda_{s}^{i}(t) & =\frac{u_{H}^{\prime}\left(c_{s}^{H}(t)\right)}{u_{i}^{\prime}\left(c_{s}^{i}(t)\right)} \quad \forall i \neq H \quad \forall t>0 \\
\lambda_{r}^{i}(t+1) & =\frac{\lambda_{s}^{i}(t)+\phi_{r}^{i}(t+1)}{1+\phi_{r}^{H}(t+1)} \quad \forall r \in \mathcal{S} \quad \forall i \neq H \quad \forall t>0
\end{aligned}
$$

Equations (15) and (16) are conditions for efficient risk-sharing, both intratemporally and intertemporally. With full commitment so $\phi_{r}^{i}(t+1)=\phi_{r}^{H}(t+1)=0$, equation (16) shows that $\lambda_{r}^{i}(t+1)=\lambda_{s}^{i}(t) \forall r \in S$. Thus for each household, the $\lambda$ is independent of both time and state. From equation (15) this means that the ratio of any two household's marginal utility of consumption is constant across states and over time. Another way to express this is to write the marginal rate of substitution for household $i$ between consumption in states $q$ and $r$ as

$$
M R S_{q, r}^{i}=\frac{\pi_{s r} u_{i}^{\prime}\left(c_{r}^{i}(t+1)\right)}{\pi_{s q} u_{i}^{\prime}\left(c_{q}^{i}(t+1)\right)}
$$

and to write the marginal rate of substitution between any two dates $t+1$ and $t$ as

$$
M R S_{t, t+1}^{i}=\frac{\delta u_{i}^{\prime}\left(c_{r}^{i}(t+1)\right)}{u_{i}^{\prime}\left(c_{s}^{i}(t)\right)}
$$

Equations (15) and (16) imply that the $M R S_{q, r}^{i}$ is equated for all households and that $M R S_{t, t+1}^{i}$ is also equated for all households.

The limited commitment solution can be seen as a compromise between the full commitment solution and the autarky solution. It allows for some risk-sharing but at the cost of not achieving allocative efficiency. First note, that risk-sharing need not be complete. Equations (15) and (16) show that the ratio of the marginal utilities of any two households is kept constant unless the sustainability constraints are binding. Using equation (15) the ratio of marginal utilities between household $i$ and household $j$ at date $t$ is

$$
R M U_{s}^{i, j}(t)=\frac{u_{i}^{\prime}\left(c_{s}^{i}(t)\right)}{u_{j}^{\prime}\left(c_{s}^{j}(t)\right)}=\frac{\lambda_{s}^{j}(t)}{\lambda_{s}^{i}(t)}
$$

Then equation (16) gives an updating equation for the ratio of the marginal utilities

$$
R M U_{r}^{i, j}(t+1)=\frac{R M U_{s}^{i, j}(t)+\phi_{r}^{j}(t+1) / \lambda_{s}^{i}(t)}{1+\phi_{r}^{i}(t+1) / \lambda_{s}^{i}(t)} .
$$

Suppose that $\phi_{r}^{i}(t+1)>0$ and $\phi_{r}^{j}(t+1)=0$, so that household $i$ has a binding sustainability constraint in state $r$ but that household $j$ is unconstrained. The updating rule shows that 
$R M U_{r}^{i, j}(t+1)<R M U_{s}^{i, j}(t)$ or that $M R S_{t, t+1}^{i}<M R S_{t, t+1}^{j}$. Thus given period $t$ consumptions, it would be beneficial at date $t+1$ to equate the marginal rates of substitution for households $i$ and $j$ by raising $c_{r}^{j}(t+1)$ and reducing $c_{r}^{i}(t+1)$. It is however, not desirable to reduce $c_{r}^{i}(t+1)$ since future consumptions would have to be raised to maintain the discounted expected utility of household $i$ and not violate its sustainability constraint and this would lead to a worse pattern of consumption from the point of view of risk sharing. If $\phi_{r}^{j}(t+1)>0$ and $\phi_{r}^{i}(t+1)=0$, then the opposite case applies, $M R S_{t+1, t}^{i}>M R S_{t+1, t}^{j}$. In the case where both households have binding sustainability constraints the inequality could go either way.

To consider the impact of the sustainability constraints on the allocative efficiency of the outcome, suppose that household $i$ has a binding sustainability constraint in some state $r$ at date $t+1$. Equation (14) shows how the the sustainability constraints modify the allocative efficiency condition. The sign of the extra term in equation (14) depends upon the sign of $\left(u_{i}^{\prime}\left(c_{r}^{i}(t+1)\right)-u_{i}^{\prime}\left(\hat{c}_{r}^{i}\left(z_{r}^{i}(t+1)\right)\right)\right)$, which depends on whether the agreed consumption is higher or lower than the optimum autarky consumption when the resources available to household $i$ are $z_{r}^{i}$. To interpret this, suppose that household $i$ increases storage at date $t$ by $\rho$ units, so that an extra unit of resources is available at time $t+1$ in each state, and suppose that this extra unit is consumed, so the benefit is $u_{i}^{\prime}\left(c_{r}^{i}(t+1)\right)$. However, the extra unit also raises the utility from autarky thus increasing the benefit to deviating from the agreement. The increase in the autarky utility is given by the envelope condition in the autarky problem, equation $(2)$, as $u_{i}^{\prime}\left(\hat{c}_{r}^{i}\left(z_{r}^{i}(t+1)\right)\right)$. If $\left(u_{i}^{\prime}\left(c_{r}^{i}(t+1)\right)-u_{i}^{\prime}\left(\hat{c}_{r}^{i}\left(z_{r}^{i}(t+\right.\right.\right.$ 1))) ) $>0$, or if $c_{r}^{i}(t+1)<\hat{c}_{r}^{i}\left(z_{r}^{i}(t+1)\right)$, then the extra storage relaxes the sustainability constraint in state $r$ next period. If $c_{r}^{i}(t+1)>\hat{c}_{r}^{i}\left(z_{r}^{i}(t+1)\right)$, then extra storage tightens the sustainability constraint. The magnitude of the term also depends on the number of binding sustainability constraints. Thus the level of storage undertaken by a household will depend on how likely it is to face binding sustainability constraints. If the last term in equation (14) is strictly positive, then current consumption of household $i$ will be lower relative to future consumption than predicted by the usual Euler equation as there is an additional return on saving due to the relaxation of the sustainability constraints. If the last term in equation (14) is strictly negative, then current consumption of household $i$ will be higher relative to future consumption than predicted by the usual Euler equation as addition storage will aggravate the sustainability constraints by making autarky more attractive.

In general it is not possible to sign the last term in equation (14). It can however, be signed if all storage can only be held communally. In this case storage does not affect 
autarky utilitity. Therefore the only modification to the programming problem is that the non-negativity constraint on storage should apply at the aggregate level instead of applying household by household. In this case, the $u_{i}^{\prime}\left(\hat{c}_{r}^{i}\left(z_{r}^{i}(t+1)\right)\right)$ term drops out of equation (14) and the third term on the right hand side of equation (14) is strictly positive provided some sustainability constraint binds in the next period.

3.2. Welfare. An interesting question to ask in the context of limited commitment is whether improved storage technologies necessarily enhance welfare. There is a possibility that they may not. Storage may widen what is technologically feasible but may also increase the payoff in autarky, restricting what is sustainable. ${ }^{6}$ We can show that enhanced storage technologies can both improve and reduce welfare with the aid of two simple examples.

First, suppose that $\rho=\infty$, so there are no storage possibilities; it requires an infinite amount of current goods to get one extra unit at the next date. Then we can use the results of Ligon, Thomas, and Worrall (1997) to conclude that if the discount factor $\delta$ is low enough, then no non-autarkic sustainable contract exits. The future is simply discounted too heavily for there to be any risk-sharing and each household ends up consuming their own income in each state at each date. The expected marginal rate of substitution for household $i$ in autarky in some state $s$ is

$$
E M R S_{t+1, t}^{i}=\frac{\delta \sum_{r=1}^{S} \pi_{s r} u_{i}^{\prime}\left(y_{r}^{i}(t+1)\right)}{u_{i}^{\prime}\left(y_{s}^{i}(t)\right)}
$$

Now suppose that storage possibilities are enhanced. In particular suppose that $\rho$ is less than the expected marginal rate of substitution in equation (17) for some household $i$ and some state $s$. Then household $i$ can improve utility by engaging in some storage which trivially provides some self-insurance against random income fluctuations.

To see the opposite extreme, again first suppose that $\rho=\infty$ so that there are no storage possibilities. Then the results of Ligon, Thomas, and Worrall (1997) show that if the discount factor $\delta$ is high enough, the first-best contract with complete risk-sharing is possible. Suppose that there is no aggregate income risk, so that complete risk-sharing implies that each household's consumption is completely stabilised. Then the expected marginal rate of substitution at the first-best optimum is $E M R S_{t+1, t}^{i}=\delta$ for all households at all time

\footnotetext{
${ }^{6} \mathrm{~A}$ similar ambiguity may arise if altruism is introduced into the model. The more altruistic are households the more they are willing to transfer to the other household but it also renders the threat to return to autarky incredible so making sustainability more difficult. For an analysis of altruism in this context see Foster and Rosenzweig (Foster and Rosenzweig 1995).
} 
periods. It is the easy to show that for $\delta$ sufficiently low, but such that the first-best contract is possible, there will be some household $i$ which at this optimum is just indifferent between sticking to the agreement and reneging in some state. If storage possibilities are introduced, but the marginal rate of transformation is still high $(\rho>\delta)$, then the first-best allocation is unchanged and storage is not utilised at the first-best optimum. However, the autarky utility is raised by the possibility of storage. Thus household $i$, which was previously indifferent between sticking to the agreement and reneging, will now find it beneficial to renege and engage only in self-insurance through storage. The first-best allocation is rendered unstainable and enhanced storage possibilities reduce welfare. In Section 5.2, we construct a numerical example to confirm this possibility and to quantify the welfare impact.

It is worthwhile to note that in contrast to this ambiguous situation, if storage can only be undertaken communally, the no-storage allocation remains a sustainable contract. Hence storage when undertaken communally can only ever push out the potential welfare frontier. ${ }^{7}$

3.3. Ex Ante Transfers. A recent paper by Gauthier, Poitevin, and González (1997) has shown how ex ante transfers may be used to improve risk-sharing in a dynamic limited commitment environment. They examine a bilateral model where one household has a constant income and the other has random income which is distributed independently and identically over time. There are no storage possibilities but households are allowed to make ex ante transfers before the state is known as well as ex post transfers after the state is realised. They show how ex ante transfers may be used to alleviate the sustainability constraints. The reasoning is as follows. Consider household 1 and suppose that its sustainability constraint will bind in some states in a particular period, but suppose that household 2's constraints never bind. In this case household 1 may be transferring less than full risk-sharing dictates. Now suppose household 1 makes an ex ante transfer before the state is known, offset by an equivalent reduction in the ex post transfer in the non-binding states but not in the binding states in such a way so as not to violate sustainability at the point of the ex ante transfer. This effectively relaxes the ex post sustainabilty constraints by allowing a larger transfer in binding states. The ex ante transfer should also take account of the impact on both the ex ante and ex post sustainability constraints of the other household, so the ex ante transfer should be chosen small enough that household 2's sustainability constraints are not violated.

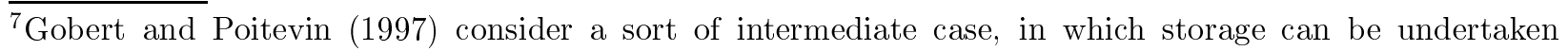
privately, but in which any savings must be forfeited if a household chooses to become an autarkist. 
It is very natural to examine ex ante transfers of the type considered by Gauthier, Poitevin and González in a model with storage as ex ante transfers can be made out of storage and the size of the ex ante transfers can be explicitly constrained by household resources. Moreover, in our model with storage, the ex ante transfers have an even more direct effect on the ex post constraints by changing the autarky payoffs. Nevertheless we can show that ex ante transfers are not beneficial in our model except possibly at the initial date.

To show this we need to explain how the model can be extended to allow for possible ex ante transfers. A similar argument can be made to that given in Section 2. The strategies of the households are extended to allow for the specification of acceptable ex ante transfers at an interim stage before the current state is known. Similar reasoning shows that the allocation depends on net transfers and is subject to additional ex ante sustainability constraints. Suppose that household $i$ is to make an ex ante transfer of $x^{i}$ to household $H$. We will assume these transfers are feasible out of current stocks, and so satisfy the non-negativity requirements $k^{i}-x^{i} \geq 0$ and $k^{H}+\sum_{i=1}^{H-1} x^{i} \geq 0$. Since a household who receives an ex ante transfer has increased autarky possibilities, the ex ante transfers have to be reflected in the ex post sustainability constraints. Thus the sustainability constraints from the previous section need to be modified as follows

$$
\begin{aligned}
U_{r}^{i} & \geq Z_{r}^{i}\left(z_{r}^{i}-x^{i}\right) \quad \forall i \neq H \quad \forall r \in \mathcal{S} \\
U_{r}^{H}\left(U_{r}^{1}, \ldots, U_{r}^{H-1} ; z_{r}\right) & \geq Z_{r}^{H}\left(z_{r}^{H}+\sum_{i=1}^{H-1} x^{i}\right) \quad \forall r \in \mathcal{S}
\end{aligned}
$$

With ex ante transfers, it is also necessary to take account of the fact that some household who is called upon to make an ex ante transfer may have an incentive to renege at that point. To prevent this any agreement will have to satisfy the following additional ex ante sustainability constraints.

$$
\begin{aligned}
\sum_{r=1}^{S} \pi_{s r} U_{r}^{i} & \geq \sum_{r=1}^{S} \pi_{s r} Z_{r}^{i}\left(z_{r}^{i}\right) \quad \forall i \neq H \\
\sum_{r=1}^{S} \pi_{s r} U_{r}^{H}\left(U_{r}^{1}, \ldots, U_{r}^{H-1} ; z_{r}\right) & \geq \sum_{r=1}^{S} \pi_{s r} Z_{r}^{H}\left(z_{r}^{H}\right)
\end{aligned}
$$

These are similar to the ex ante sustainability constraints considered by Gauthier, Poitevin and González. If there are ex ante transfers then there is some household $i$ which makes a positive ex ante transfer, $x^{i}(t+1)>0$ and some household $j$ which receives a positive ex ante 
transfer, $x^{j}(t+1)<0$. Now consider the following changes. Reduce the ex ante transfer of household $i$ by one unit and increase the ex ante transfer of household $j$ by one unit. ${ }^{8}$ There is no net effect on the ex ante transfer to household $H$. The ex post transfer of household $i$ at date $t, \tau_{s}^{i}(t)$ is increased by $\rho$ units and the ex post transfer of household $j$ is reduced by $\rho$ units. The consumption of each household is to be left unchanged. Thus storage at date $t$ by household $i$ is reduced by $\rho$ units and storage by household $j$ is increased by $\rho$ units. The net effect is that $k^{i}(t+1)+x^{i}(t+1)$ and $k^{j}(t+1)+x^{j}(t+1)$ are left unaltered. Note that it is feasible to reduce storage for household $i$ since by assumption $k^{i}(t+1)+x^{i}(t+1) \geq 0$. Since storage at date $t+1$ is unaffected by these changes, the ex post sustainability constraints, (18) and (19) continue to hold.

Now consider the ex ante sustainability constraints, (20) and (21). Household $H$ is unaffected by the changes, so (21) continues to hold. Household $j$ receives a transfer, so will have no incentive to renege at the ex ante stage. To see this formally recall that $Z_{r}^{j}\left(z_{r}^{j}-x^{j}\right)$ is increasing, so $Z_{r}^{j}\left(z_{r}^{j}-x^{j}\right)>Z_{r}^{j}\left(z_{r}^{j}\right)$ for $x^{j}<0$. Thus the ex post constraints, (18), imply that the ex ante constraints (20) for household $j$ are not binding. For household $i, k^{i}(t)$ is reduced by one unit and since $Z_{r}^{i}\left(z_{r}^{i}\right)$ is increasing, the constraint (20) is actually relaxed by the reduction in $x^{i}(t+1)$. Thus if there are ex ante transfers they can be reduced to zero without diminishing welfare.

This argument works by substituting storage for any ex ante transfers. For example, in the above household $i$ makes an effective ex ante transfer to household $j$. The same outcome can be achieved by dictating that household $j$ should store more in the previous period and household $i$ should store less. One point where this argument breaks down is the initial period. Thus there might well be a role for ex ante transfers at the initial date in order to alleviate some sustainability constraints.

\section{Randomized Strategies and Computation}

As noted above, one possible problem is that our constraint set may be nonconvex. Permitting public randomization convexifies the constraint set. A further practical benefit is that the use of randomization gives us the means to compute solutions to parameterized versions of the game.

\footnotetext{
${ }^{8}$ One of households may be household $H$ which receives a transfer of $\sum_{i=1}^{H-1} x^{i}$. In this case making one adjustment implies the other. In what follows it is assumed $i, j \neq H$, but it is easy to see how the argument works if one of the households is household $H$.
} 
As a first, simplifying step, let $H=2$, and suppose that the distribution of $\left(y^{1}, y^{2}\right)$ is independent across time, with the probability of state $s$ given by $\pi_{s}$. Consider the problem facing a social planner who seeks to maximize some weighted sum of expected discounted utilities of the two agents. The planner takes as given a "planning weight" $\theta$, but in any state $s$ and for any stock of assets $z$ is free to choose the promised utility $U^{1}$ for agent one, solving the problem:

$$
\max _{U_{s}^{1}} \sum_{s \in \mathcal{S}} \pi_{s}\left\{\theta U_{s}^{1}+(1-\theta) U_{s}^{2}\left(U_{s}^{1} ; z\right)\right\}
$$

Asserting for the moment that $U_{s}^{2}(\cdot ; z)$ is a strictly concave function of $U_{s}^{1}$ and is continuously differentiable, the first order conditions for this problem require that

$$
-\frac{\partial U_{s}^{2}}{\partial U_{s}^{1}}\left(U_{s}^{1} ; z\right)=\frac{\theta}{1-\theta} .
$$

The planning weight $\theta$ is related to the Lagrange multiplier $\lambda$ by $\theta=\lambda /(1+\lambda)$, and the ratio of expected marginal values is determined solely by $\theta$.

We next introduce the planner's value function. The assumption of intertemporal independence in the endowment process allows us to reduce the size of the state space for this problem. Because the planner will maximize some welfare function subject to satisfying sustainability constraints for both players, we introduce a pair of value functions $V_{1}(\theta, z)$ and $V_{2}(\theta, z)$ in lieu of $U_{s}^{1}$ and $U_{s}^{2}\left(U_{s}^{1} ; z\right)$. The planner's problem is then

$$
\begin{aligned}
& g(\theta, z)=\underset{c_{1}, c_{2}, k^{1}, k^{2},\left(\theta_{s}\right)_{s} \in \mathcal{S}}{\operatorname{argmax}} \sum_{s \in \mathcal{S}} \pi_{s}\left\{\theta u^{1}\left(c_{1}\right)+(1-\theta) u^{2}\left(c_{2}\right)+\right. \\
&\left.\delta\left[\theta V_{1}\left(\theta_{s}, y_{s}^{1}+y_{s}^{2}+k^{1}+k^{2}\right)+(1-\theta) V_{2}\left(\theta_{s}, y_{s}^{1}+y_{s}^{2}+k^{1}+k^{2}\right)\right]\right\}
\end{aligned}
$$

such that the consumption allocation is feasible (ex post),

$$
c_{1}+c_{2}=z-\rho\left(k^{1}+k^{2}\right)
$$

and such that neither agent has an incentive to revert to autarky (also ex post),

$$
V_{i}\left(\theta_{s}, y_{s}^{1}+y_{s}^{2}+k^{1}+k^{2}\right) \geq Z_{i}\left(k^{i}+y_{s}^{i}\right)
$$

for $i=1,2$, and for all $s \in \mathcal{S}$. There are several things to note about this problem. First, notice that the first order conditions with respect to consumptions $c_{1}$ and $c_{2}$ suffice to solve for consumptions as a function of $\left(\theta, z, k^{1}, k^{2}\right)$; the sustainability constraints do not play a 
role in the allocation of consumption within a given period. Following Hayashi (1996), we use this fact to eliminate individual consumptions as a choice object, and substitute 'reduced form' utilities $u^{i}(\theta, x)$ for $u^{i}\left(c_{i}\right)$, where $x$ denotes the aggregate resources to be allocated to consumption in the period. Note that this quantity differs from the state variable $z$ introduced earlier in that $x$ is net of savings; thus $x=z-\rho\left(k^{1}+k^{2}\right)$.

Note the dependence of the optimal policy $g$ on the agents' value functions; the single functional equation given above can't be used to uniquely solve for the three functions $V_{1}$, $V_{2}$, and $g$. Still, there is an obvious connection between the agent's value functions and the social welfare function maximized by the planner which will permit us to solve the system. In particular, when $\left(k^{1}, k^{2},\left(\theta_{s}\right)_{s \in \mathcal{S}}\right)$ are chosen according to the optimal policy from the planner's problem, then $V_{i}$ must satisfy

$$
V_{i}(\theta, z)=\sum_{s \in \mathcal{S}} \pi_{s}\left\{u\left(\theta, z-\rho\left(k^{1}+k^{2}\right)\right)+\delta V_{i}\left(\theta_{s}, k^{1}+k^{2}+y_{s}^{1}+y_{s}^{2}\right)\right\}
$$

$i=1,2$. Thus, a solution to this system of functional equations is a triple $\left(V_{1}, V_{2}, g\right)$, where $V_{1}$ and $V_{2}$ are the agents' value functions, and where $g$ is the planner's optimal policy function.

With this sequence of simplifications in hand, we are ready to introduce lotteries. In particular, define an event space $\Omega=\left\{\left(k^{1}, k^{2}, y^{1}, y^{2}, \theta^{\prime}\right)\right\}$, assumed to be finite and discrete. The planner now solves her problem by assigning a probability $\pi(\omega)$ to every element $\omega \in \Omega$. The resulting set of probabilities must define a valid probability mass function, and must be consistent with the exogenous objective probabilities of the realizations of $\left(y^{1}, y^{2}\right)$. The planner solves

$$
\begin{array}{r}
\pi^{*}(\omega \mid \theta, z)=\underset{\{\pi(\omega)\}_{\omega \in \Omega}}{\operatorname{argmax}} \sum_{\omega} \pi(\omega)\left\{\theta u^{1}\left(\theta, z-\rho\left(k^{1}+k^{2}\right)\right)+(1-\theta) u^{2}\left(\theta, z-\rho\left(k^{1}+k^{2}\right)\right)\right. \\
\left.+\delta\left[\theta V_{1}\left(\theta^{\prime}, y^{1}+y^{2}+k^{1}+k^{2}\right)+(1-\theta) V_{2}\left(\theta^{\prime}, y^{1}+y^{2}+k^{1}+k^{2}\right)\right]\right\}
\end{array}
$$

such that objective probabilities are respected,

$$
\sum_{\left\{\omega \in \Omega \mid\left(y^{1}, y^{2}\right)=\left(\bar{y}^{1}, \bar{y}^{2}\right)\right\}} \pi(\omega)=\operatorname{Pr}\left(\bar{y}^{1}, \bar{y}^{2}\right)
$$

for all $\left(\bar{y}^{1}, \bar{y}^{2}\right)$; and such that the distribution of savings is independent of income realizations (this captures the idea that savings are chosen before income is realized),

$$
\operatorname{Pr}\left(\bar{y}^{1}, \bar{y}^{2}\right) \sum_{\left\{\omega \in \Omega \mid\left(k^{1}, k^{2}\right)=\left(\bar{k}^{1}, \bar{k}^{2}\right)\right\}} \pi(\omega)=\sum_{\left\{\omega \in \Omega \mid\left(k^{1}, k^{2}, y^{1}, y^{2}\right)=\left(\bar{k}^{1}, \bar{k}^{2}, \bar{y}^{1}, \bar{y}^{2}\right)\right\}} \pi(\omega)
$$


for all $\left(\bar{k}^{1}, \bar{k}^{2}, \bar{y}^{1}, \bar{y}^{2}\right)$. Finally, we require that the sustainability constraints are satisfied for all events which happen with positive probability, or

$$
\pi(\omega)\left[V_{i}\left(\theta^{\prime}, k^{1}+k^{2}+y^{1}+y^{2}\right)-Z_{i}\left(k^{i}+y^{i}\right)\right] \geq 0
$$

for $i=1,2$ and for all $\omega$. Of course, in order for this collection of probabilities to constitute a probability mass function, $\pi(\omega)$ must also lie in $[0,1]$, and must sum to one (this last condition is implied by (24), so long as $\operatorname{Pr}\left(y^{1}, y^{2}\right)$ is itself a valid pmf).

The agents' value functions must then satisfy

$$
V_{i}(\theta, z)=\sum_{\omega \in \Omega} \pi^{*}(\omega \mid \theta, z)\left[u^{i}\left(\theta, z-\rho\left(k^{1}+k^{2}\right)\right)+\delta V_{i}\left(\theta^{\prime}, k^{1}+k^{2}+y^{1}+y^{2}\right)\right]
$$

for $i=1,2$. As above, a solution to this system of functional equations is a triple; in this case $\left(V_{1}, V_{2}, \pi^{*}\right)$.

One can employ the following algorithm to find a solution. First, solve the autarkic problem. Second, guess some initial value for $V_{1}$ and $V_{2}$. Third, taking the guessed value functions as given, solve the problem of maximizing (23) subject to (24), and (26). Call the optimal pmf for this problem $\pi^{*}\left(\theta^{\prime} \mid \theta, z_{1}, z_{2}\right)$. Fourth, use (27) to update the guess for $V_{i}$, and finally, go to step three.

\section{Computed Examples}

In this section we present results from three computed examples. For each of these examples, we assume that households' utility functions are given by $u^{i}(c)=\log (c)$. In the first example, we examine the constrained efficient use of storage in an economy with both individual and aggregate risk. We construct our second example to illustrate our point that the introduction of storage may be welfare-reducing, and compute the limiting distribution of assets and consumption in an economy with no aggregate risk. Our third example extends our earlier analysis slightly_instead of requiring assets $k^{i}$ to be non-negative, we simply bound them, but permit them to be negative. This permits us to interpret these assets as ex ante transfers. In equilibrium, households use these transfers to 'post a bond,' which has the effect of relaxing the sustainability constraints.

5.1. Example with storage. This example illustrates the role of storage in a simple economy with both individual and aggregate risk. Each of two households receives an endowment 
each period. The endowment process is iid over both time and agents, with

$$
y^{i}= \begin{cases}1 & \text { with probability } 0.1 \\ 2 & \text { with probability } 0.9\end{cases}
$$

Thus, each household faces a ten per cent chance of a fifty per cent loss in any period, while in the aggregate the risk of a fifty per cent loss is one per cent.

To ameliorate these risks, each household can store some quantity in $[0,1]$, with $\rho=1$, so the intertemporal technology is something like storage of the consumption good, with no depreciation. The discount factor in this example is 0.8 , so the impatience of the households means that the utility cost associated with storage is considerable.

The expected storage of household one is depicted in Figure 1; household two's storage is symmetric to household one's; aggregate storage for this example is shown in Figure 2. There are three things to note about these figures. First, storage is monotonically increasing in the level of initial assets, which is scarcely novel. More novel is that the distribution of assets across households depends critically on $\theta$. In particular, assets are given to the household with greater consumption. The intuition for this is as follows. Any household which engages in storage increases the probability of having its sustainability constraint bind, since the returns to autarky improve as it engages in more private storage. Thus, if there is to be storage, it ought to be done by households which are unlikely to have such a binding constraint. In this iid environment, these are precisely the households which receive a large surplus from the informal insurance arrangement; household one if $\theta$ is large, and household two if $\theta$ is small. The intermediate case, when $\theta$ is near one half, has the feature that either household is quite likely to have a binding sustainability constraint in the next period, so relatively little of the consumption good is stored by either household.

Figure 2 shows storage both for household one and in the aggregate. Though unaffected by the upper bound on storage, the pattern of storage across households continues to depend critically on the distribution of surplus across households.

5.2. Storage may be welfare-reducing. This example is meant to illustrate the point, made in the text, that the introduction of an intertemporal technology may actually reduce the welfare associated with the efficient contract in the limited commitment environment. 


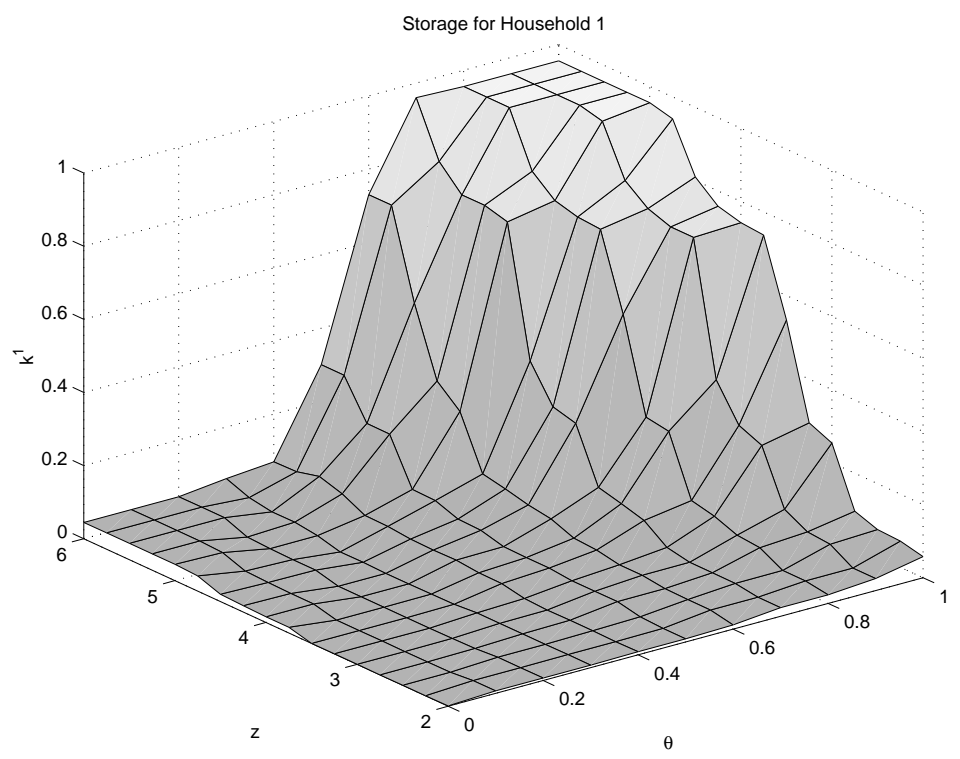

Figure 1. Household 1's Expected Storage

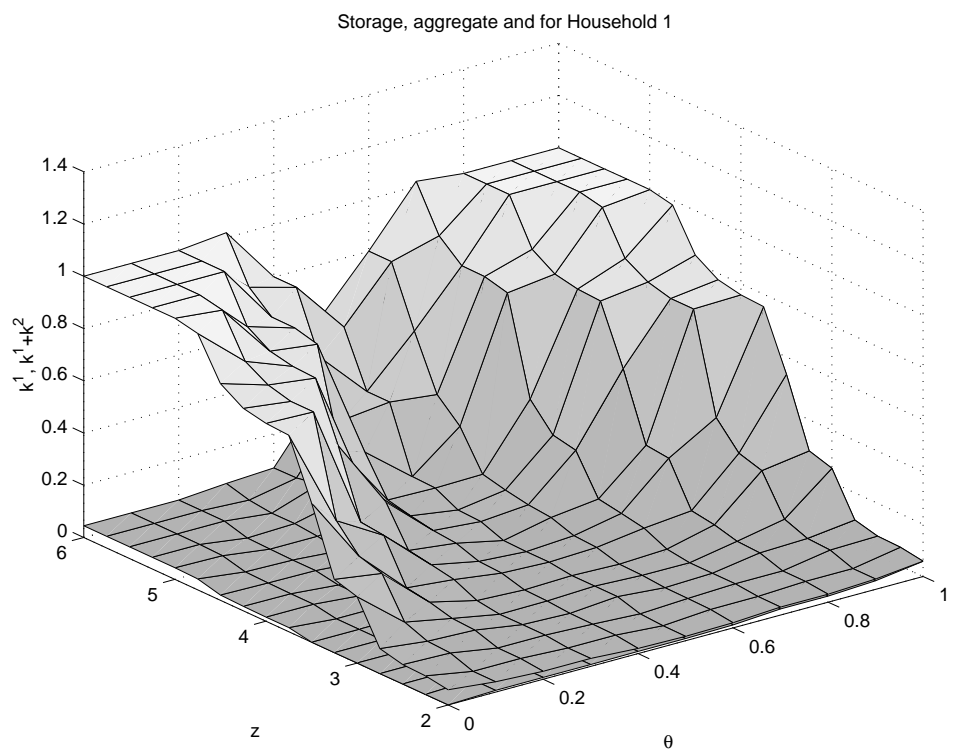

Figure 2. Expected Storage. This figure displays both aggregate storage and storage for household 1, although household 1's storage is largely obscured.

This somewhat perverse result is a consequence of the fact that introducing savings opportunities may increase the value associated with autarky (because the introduction of savings permits the household to self-insure), and thus may reduce the set of sustainable allocations.

To construct the example, we began by specifying identical logarithmic utility functions for each of two households, and an endowment process with no aggregate uncertainty. In 


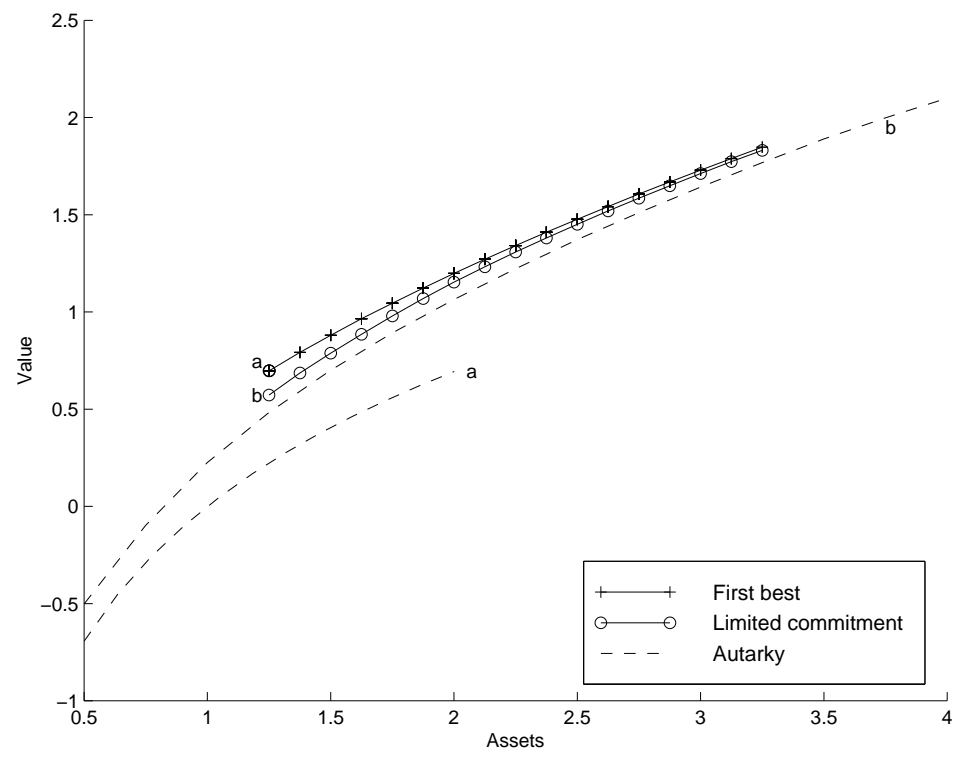

Figure 3. Value and Capital

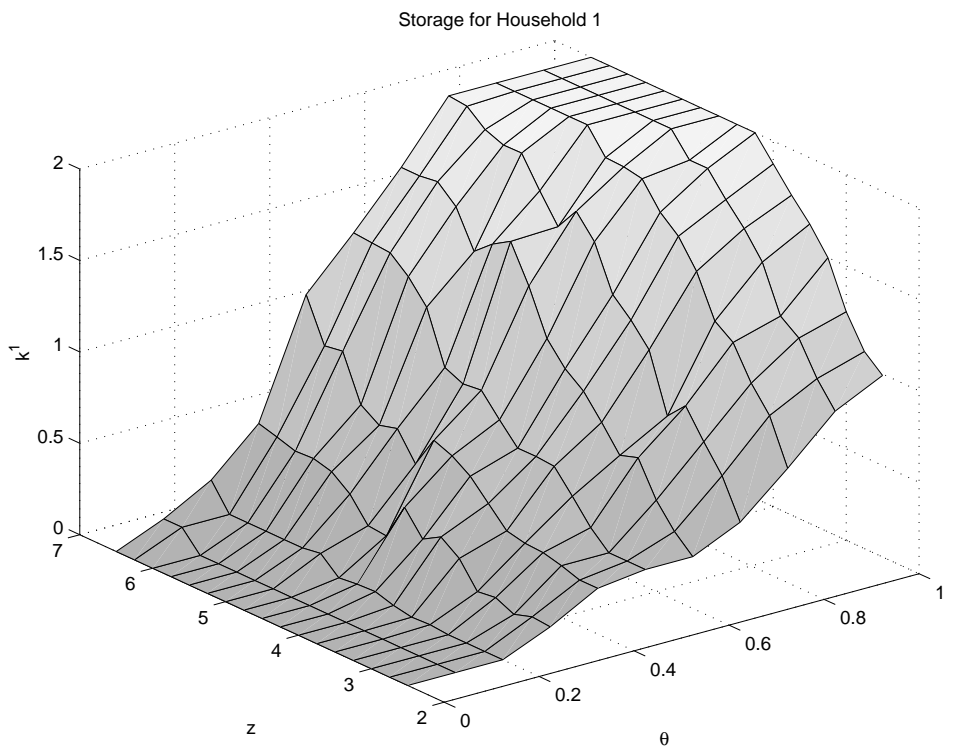

FiguRE 4. Savings for Household 1

particular, we choose

$$
\left(y^{1}, y^{2}\right)= \begin{cases}(1 / d, d) & \text { with probability } 1 / 2 \\ (d, 1 / d) & \text { with probability } 1 / 2\end{cases}
$$




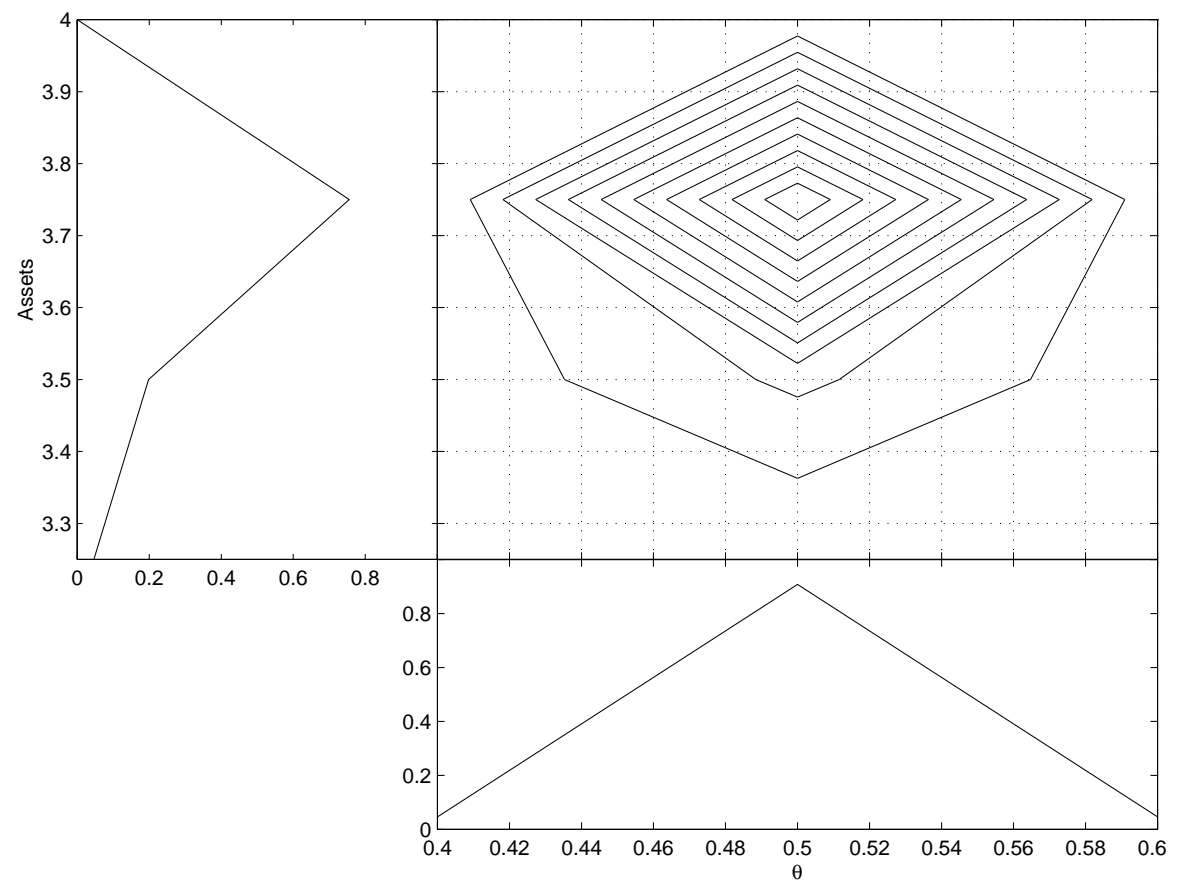

Figure 5. Steady State Distribution of Assets and $\theta$. The central figure is the level sets of the joint pdf of assets and $\theta$; each line indicates a decile set. The figures on the sides indicate the marginal distributions.

We set $d=2$, and proceeded to compute efficient allocations in six different economies. In particular, we computed solutions to first best, autarkic, and limited commitment economies; both with and without any storage possibilities.

To construct the first best economy, we considered only the symmetric allocations we'd expect to observe when $\theta=0.5$. In the absence of storage, each household simply consumes one half of the aggregate endowment; that is, consumes 1.25 with certainty. We choose the smallest discount factor such that no sustainability constraints would bind, in this example about 0.68 , and set the storage cost parameter $\rho=1.1 \delta$. With no consumption uncertainty and the rate of return to storage less than the rate of time discount, households will prefer consuming to saving, so the first best allocation is the same either with or without storage possibilities. The value of assets under the first best is shown as the uppermost value function in Figure 3 (marked with '+' signs).

Note that in the absence of any intertemporal technology, an autarkist in this example must consume either $d$ or $1 / d$, each with probability $1 / 2$; as a consequence, the ex ante expected, discounted utility is zero under autarky. As a consequence, ex post the value of autarky without storage is simply $\pm \log (d)$, and doesn't depend on the discount factor $\delta$. 


\begin{tabular}{lcc}
\hline \hline & No Storage & Storage \\
\hline First best & $0 \%$ & $0 \%$ \\
Autarky & $60 \%$ & $20 \%$ \\
Limited commitment & $0 \%$ & $11 \%$ \\
\hline
\end{tabular}

TABle 1. Welfare Cost of Storage. The entries in this table indicate the percentage increase in assets necessary to reach the first best level of utility.

The value of autarky without storage is illustrated in Figure 3, as the dashed line marked with an 'a.' The largest value on this line (where assets are equal to 2) is exactly equal to the smallest value under the first best allocation (where assets are equal to 1.25). One useful measure of the welfare loss associated with autarky is the increase in assets held by an autarkist necessary to yield the same level of utility associated with the first best at the original level of assets: in this case this increase is 60 per cent, and is indicated in Table 1.

With storage (and with the other parameters specified above for the first best allocation) the value of stored assets under autarky is given by the dashed line marked with a 'b' in Figure 3. Note that the welfare improvement over autarky without storage is quite considerable; the compensating increase in assets relative to the first best is only 20 per cent.

Turning our attention to the limited commitment economies, recall that we've chosen $\delta$ such that the limited commitment economy without storage (just) achieves the first best by construction. Because there is no storage, and because aggregates are constant, the value function is defined only at a point, at the circle marked with an 'a' in Figure 3, which coincides with the lower end of the curve of first best values. As we've seen, the introduction of storage increases the value of autarky, but in this example can't improve outcomes in the constrained efficient economy because of the lack of aggregate uncertainty and because we're looking only at the symmetric case where $\theta=0.5$. In fact, by tightening the sustainability constraints, the introduction of a storage technology reduces welfare under the efficient contract by about eleven percent.

Under the example of limited commitment with storage, households resort to some level of precautionary savings despite the fact that there is no aggregate uncertainty and the rate of return to savings is less than the rate of time preference. Household one's asset holdings are shown in Figure 4; household two's assets are, of course, identical, but reflected across the plane defined by $\theta=0.5$. 


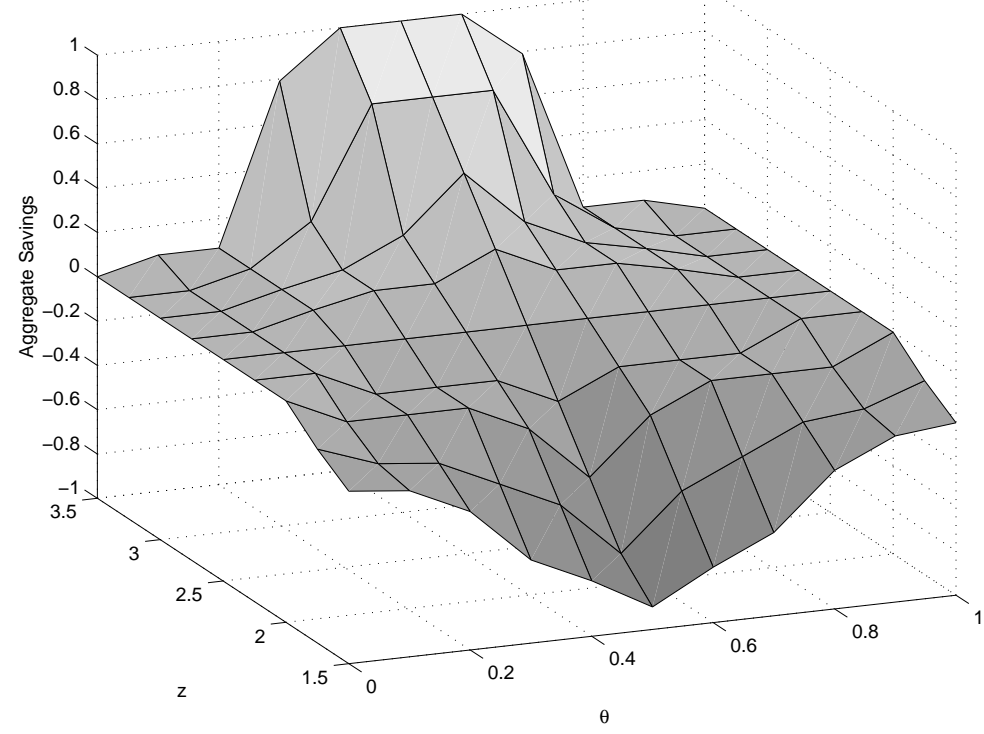

Figure 6. Aggregate Storage

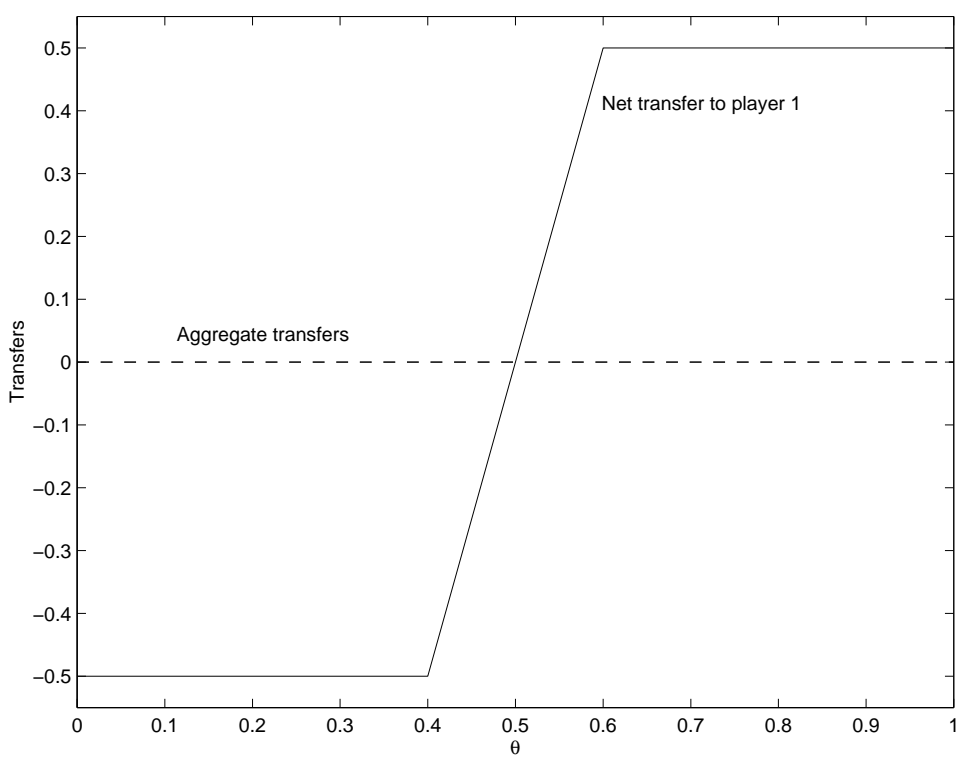

Figure 7. Ex Ante Transfers

Figure 5 displays the steady-state distribution of assets and $\theta$; the central figure shows the level curves of the joint pdf, each curve corresponding to a decile; the remaining figures display the marginal distributions.

5.3. Storage as an ex ante transfer. In the examples given above, there were two countervailing effects from engaging in storage: first, storage helps to smooth aggregate resources 
over time; but second, individual storage may aggravate the commitment problem by making autarky more attractive.

In this example, we permit both positive and negative storage. Negative storage has a natural interpretation as credit, of course, but even in the absence of credit, a negative level of storage by one household may be interpreted as a transfer to the second household, provided that the second household's storage is positive. This implicit transfer may be interpreted as "posting a bond" by the household whose sustainability constraint is more likely to be binding. Gauthier, Poitevin, and González (1997) has a similar result on the welfare consequences of ex ante transfers in an economy with limited commitment, but only when aggregate storage is zero; our results here suggest that their finding can be extended to economies with considerably richer intertemporal technologies.

In this section, we use the same endowment process as in Section 5.2, but with $d=2$. The discount factor $\delta$ is set equal to the price of a unit bond, $\rho$. This fact, combined with the stationarity of the income process and the lack of any aggregate income risk implies that an aggregate storage of zero is a steady state. This means that for $z=2.5$, we predict that in an efficient equilibrium there will be no net storage, regardless of the distribution of utility. This prediction is confirmed by Figure 6. An accompanying prediction is that for $z>3$, aggregate storage will be positive, while for $z<3$, storage ought to be negative unless some of the sustainability constraints are binding. This prediction is also confirmed by the figure; there is no aggregate storage at distributional extremes, because the value of 'posting a bond' exceeds the value of aggregate storage.

The lack of variation in aggregate storage in the steady state masks a great deal of individual activity. Figure 7 shows the storage engaged in by household one at the steady state equilibrium for which $z=2.5$. One can see that for values of $\theta$ less than one half, household one posts a bond of $1 / 2$; for values of $\theta$ greater than one half, household two posts a bond, which household one holds.

\section{CONClusion}

We've examined a dynamic game of mutual insurance when households can also choose to self-insure, and have the option of reneging on any mutual insurance agreement. Accordingly, any mutual insurance arrangements must be self-enforcing. Permitting individual savings has three effects on these self-enforcing arrangements. First of all, when the the aggregate 
endowment is uncertain, individual savings may help to smooth aggregate consumption. Second, a household with large savings may find autarky relatively attractive, and so permitting savings can have the effect of limiting the scope of mutual insurance. Third, households can use their ability to save as a partial substitute for commitment-by transferring savings from one household to another, the first household in effect posts a bond which she forfeits should she renege.

The first and third effects mentioned above improve ex ante welfare, but the second tends to reduce it, so overall the effect of savings opportunities on welfare is ambiguous. However, two other interesting features emerge from this game. First, consumption in a efficient subgame perfect equilibrium obeys a modified Euler equation. In particular, households with a small surplus from the mutual insurance arrangement will also be 'liquidity constrained,' in the sense that those households' intertemporal marginal rate of substitution will be greater than the intertemporal marginal rate of transformation.

In contrast to the literature on liquidity constraints, it's important to note that households in our model face a liquidity constraint not because they hold few assets, but rather they hold few assets and face a liquidity constraint because efficient allocation given the distribution of promised utilities and given the stock of aggregate resources demands it. Households facing a liquidity constraint will find autarky less attractive, because their expected marginal utility is larger in future periods. These same households may be assigned low levels of savings for the same reason; if they were to hold large stocks of assets, autarky would be relatively more attractive.

Second, the distribution of storable assets becomes a key part of the equilibrium. In the standard analysis of competitive equilibrium (when households have identical preferences), those households with more assets will also receive more consumption. The game presented in this paper turns this result on its head-households with more consumption are apt to be assigned more assets. What emerges is a theory of a dynamic distribution, in which shifts in the ownership of storable assets help to support an equilibrium in which the owners of those assets also hold a larger claim to the aggregate endowment.

\section{APPENDIX}

The appendix shows how the equations (14)-(16) are derived from the first-order conditions to the dynamic programming problem of Section 2 . 
First, differentiating with respect to $c_{s}^{i}(t)$ gives

$$
u_{H}^{\prime}\left(c_{s}^{H}(t)\right)=\lambda_{s}^{i}(t) u_{i}^{\prime}\left(c_{s}^{i}(t)\right), \quad \forall i \in \mathcal{H}
$$

where $\lambda_{s}^{H}(t) \equiv 1$. Rearranging (A.1) gives equation (15) in the text. Next differentiating with respect to $z_{r}(t+1)$ gives

$$
\begin{aligned}
& \rho \lambda_{s}^{i}(t) u_{i}^{\prime}\left(c_{s}^{i}(t)\right)=\delta \sum_{r=1}^{S} \pi_{s r} \frac{\partial U_{r}^{H}(\cdots)}{\partial z_{r}(t+1)}\left(1+\phi_{r}^{H}(t+1)\right) \\
& \quad-\delta \sum_{r=1}^{S} \pi_{s r} \frac{\partial Z_{r}^{i}\left(z_{r}^{i}(t+1)\right)}{\partial z_{r}(t+1)} \phi_{r}^{i}(t+1)+\omega^{i}(t+1) \quad \forall i \in \mathcal{H}
\end{aligned}
$$

and differentiating with respect to the future expected discounted utilities $U_{r}^{i}(t+1)$ gives

$$
\lambda_{s}^{i}(t)=-\frac{\partial U_{r}^{H}(\cdots)}{\partial U_{r}^{i}(t+1)}\left(1+\phi_{r}^{H}(t+1)\right)-\phi_{r}^{i}(t+1) \quad \forall i \neq H
$$

There are also the following envelope conditions:

$$
\begin{aligned}
& \frac{\partial U_{s}^{H}(\cdots)}{\partial U_{s}^{i}(t)}=-\lambda_{s}^{i}(t) \quad \forall i \neq H \\
& \frac{\partial U_{s}^{H}(\cdots)}{\partial z_{s}(t)}=-\lambda_{s}^{i}(t) u_{i}^{\prime}\left(c_{s}^{i}(t)\right) \quad \forall i \in \mathcal{H}
\end{aligned}
$$

Advancing (A.4) and (A.5) forward by one period gives

$$
\begin{aligned}
& \frac{\partial U_{r}^{H}(\cdots)}{\partial U_{r}^{i}(t+1)}=-\lambda_{r}^{i}(t+1) \quad \forall i \neq H \\
& \frac{\partial U_{r}^{H}(\cdots)}{\partial z_{r}(t+1)}=-\lambda_{r}^{i}(t+1) u_{i}^{\prime}\left(c_{r}^{i}(t+1)\right) \quad \forall i \in \mathcal{H}
\end{aligned}
$$

where $\lambda_{r}^{H}(t+1) \equiv 1$. Then substituting (A.6) into (A.3) gives (16) and substituting (A.7) into (A.2) gives (14) in the text. 


\section{REFERENCES}

Bulow, J. and K. Rogoff (1989, March). Sovereign debt: Is to forgive to forget? American Economic Review 79, 43-50.

Fafchamps, M. (1995). Risk sharing, quasi-credit, and the enforcement of informal contracts. Manuscript.

Foster, A. and M. Rosenzweig (1995). Imperfect commitment, altruism and the family: Evidence from transfer behaviour in low-income rural areas. Manuscript.

Gauthier, C., M. Poitevin, and P. González (1997). Ex ante payments in self- enforcing risk-sharing contracts. Journal of Economic Theory 76, 106-144.

Gobert, K. and M. Poitevin (1997, May). Contrat dynamique de partage de risque avec contraintes d'engagement et épargne. Série Scientifique 97s-23, CIRANO, Montréal.

Hall, R. E. (1978). Stochastic implications of the life cycle-permanent income hypothesis: Theory and evidence. Journal of Political Economy 86, 971-987.

Hayashi, F. (1996). Analysis of household saving: Past, present, and future. The Japanese Economic Review 47(1), 21-33.

Kletzer, K. and B. Wright (1996). Sovereign debt as intertemporal barter. Manuscript.

Kocherlakota, N. R. (1996). Implications of efficient risk sharing without commitment. The Review of Economic Studies 63(4), 595-610.

Ligon, E., J. P. Thomas, and T. Worrall (1997). Informal insurance arrangements in village economies. http://are. berkeley.edu/ ligon/Papers/ltw.ps.

Platteau, J.-P. (1996). Mutual insurance as an elusive concept in traditional rural societies. Forthcoming in Journal of Development Studies.

Thomas, J. P. and T. Worrall (1988). Self-enforcing wage contracts. Review of Economic Studies 55, 541-554.

University of CAlifornia, Berkeley

E-mail address: ligon@are.berkeley.edu

UNIVERSITY OF WARWICK

KeELe University 